\title{
The Art of Primitive Peoples
}

$\mathrm{A}^{\mathrm{N}}$ exhibition of the art of primitive peoples, $A$ which will remain open until the end of July, is now on view at the Burlington Fine Arts Club, 17 Savile Row, London, W.1. It covers a sufficiently wide field to afford an opportunity for comparing and contrasting the ideals and achievement of the æsthetic sense among peoples of a widely differing cultural history and geographical environment, and of estimating how far, if at all, a common element is to be discerned in the development of artistic principles in varied conditions of race, technical skill and material employed as the medium of expression. While technique varies considerably in the specimens shown in the present exhibition, it is striking at a first glance how little, relatively, the tools employed, whether of stone, shell or metal, affect the 'polish' of the finished product. Hence, while it is true that this collection contains some of the finest known examples of so-called primitive art -it is indeed a possible criticism of the exhibition that it includes so little that is crude, but at the same time scientifically instructive-the general level of execution is higher than might reasonably be expected. There are few specimens that fail to attain the highest possible degree of finish of which the artist's intention was susceptible. The decorative designs, for example, applied in Polynesia to nearly every object of wood, even in daily use, such as the paddle from Austral Islands (No. 132) or the Maori tattooed head (No. 261), though carved with stone or shell, are often so delicately executed as to have an apparent superficial texture of lacework.

The peoples whose art is illustrated in the exhibition are widely distributed geographically. Both in number and artistic achievement the exhibits from West Africa hold first place. The remainder of the exhibits are drawn mainly from the South Seas, the most important sections being that of New Guinea and the art of the Maoris of New Zealand; but the Solomons, Easter Island, the Sandwich Islands, the Marquesas and other groups are also represented. America has been expressly excluded, as an exhibition of American art was held by the Club a few years ago; but there are a few masks and other objects made by the Indians of the North-West Coast and a collection of Eskimo ivory carvings. One case contains a miscellaneous collection of objects from areas not represented elsewhere in the exhibition. Here some bone needle-holders from Borneo and New Guinea show an incised scroll pattern which, in the use of a southeastern Asiatic foliate motif highly conventionalised, contrasts markedly with other exhibits.

In an exhibition of this kind it is difficult to keep the anthropological and the artistic interests nicely balanced, and the rarity or ritual purpose of certain objects may tend to absorb attention to the neglect of artistic merits. Such, indeed, may be the fate of the whole of the collection of objects from the Sepik River, New Guinea, lent by the University Museum of Archæology and Ethnology, Cambridge, among which are the remarkable and unique ceremonial feather-covered boards, of which the longest is $4 \mathrm{ft}$. 9 in. long (No. 245), and the orator's stool, which is beaten violently while the orator speaks, but is never sat on (No. 33).

An exhibition of 292 items, each of which anthro. pologically or artistically-and usually on both counts-is a treasure, precludes any attempt at detailed description. A bare mention of a few of the more striking specimens must suffice. The important exhibit of examples of West African art-statuettes and carvings in wood and ivory and castings in bronze-includes a number of examples of the wellknown Benin art. The general character of this group of exhibits will not be entirely unfamiliar to the public, thanks to the recent exhibition of African art. Those, however, who know it only from the illustrations which appear in books on African art, can have little conception of the vitality and purpose, which override faults in proportion, according to European standards, when these examples are seen in the round. Among the more striking examples here are the Benin flute-player (No. 68) and the carved ivory mask from Benin (No. 110); but even more remarkable in its kind is the carved ivory sistrum with beaters, also from Benin. There is also a wonderful expression of purpose, which is emphasised by the disproportionately short legs of the figures, in the wooden head-rest supported on two females with arms entwined, from the Congo (No. 126). The list of examples deserving prolonged study might even be extended to the whole of this section, if other exhibits did not equally demand attention.

Though less spectacular, the small collection of Eskimo ivory carvings is one of the most attractive and arresting features in the exhibition. It consists of male and female figures, a mask, a number of toggles, arrow straighteners, amulets and bow-drills. All, but particularly the amulets and toggles in the form of seals, whales and other fauna, display a wonderful realism and appreciation of the niceties of animal forms. The gems of this collection, however, are the ivory bows for fire-drills (Nos. 48-55), which are covered with figures of animals or with hunting and fishing scenes incised in a space which, at most, does not exceed three-quarters of an inch in breadth. These pictures, minute as they are, are instinct with vitality, full of action, and almost photographic in their truth to life.

The exhibits from the South Seas, and especially the section devoted to the Maori art of New Zealand, includes some choice specimens; some are already well known, while others, such as the War God from Hawaii collected by Capt. Cook on his last voyage (No. 189), are of historic interest. The use of 'mother of pearl' as an inlay, especially in the human figure, is well illustrated in the Solomon Islands group, while of all the representations of the human form in this section, the emaciated figures from Easter Island, with their peculiar facial character, continue to arouse the most interest, and to prompt what is, unfortunately, in the circumstances, a not very profitable ethnological speculation, New Guinea, outside the Sepik River area already mentioned, is well represented in a number of specimens in which the ethnological interest is perhaps greater than the purely artistic. Among these are specimens from Dr. A. C. Haddon's collections from the Torres Straits.

The list of objects to which reference should be made is far from exhausted; but enough has been said to indicate the importance of the collection as a whole as a demonstration of the artistic capacity of those backward peoples, to whom few outside the ranks of the student are habituated to conceding recognition in this field of activity. 